\title{
In praise of libraries
}

John Launer

In a month that sees an international conference on Residency Education and Care in the Digital Age, ${ }^{1}$ it may seem a little churlish to write in praise of libraries. However, having shown off my social media savvy last year by promoting the use of Twitter, ${ }^{2}$ I now want to redress the balance a little. Until very recently-even when today's medical trainees were born -libraries were the principal source of medical knowledge. Indeed, modern medicine was built on the foundation of what people had learned in them, or through the books and journals they borrowed there. In spite of all the advantages of new technologies, traditional libraries offer as much potential for learning as all the gadgets and search engines in the world, if not more. If you visit the library in your hospital or medical college, you will still find your most learned colleagues sitting there, poring over the printed page rather than staring at a screen. We should value libraries as places for study, and to fight for their continuation.

I have always had a personal affection for libraries. Growing up, I lived within walking distance of a wonderful public library where I spent hours browsing the shelves. One of the joys of doing this was serendipitous reading: I came across whole subjects I would never have known about, unless I had been attracted by a colourful cover or an arresting title. The pleasure that comes from discovering knowledge in this way is far greater than anything you can get by surfing the webfor adults as well as children, and in medical libraries as much as in public ones. Try visiting any library during the next week and allow yourself half an hour to browse at random, without distraction. Almost certainly, you will come away with some unexpected and enduring shift in your understanding of the world, quite different from anything you can recall from looking at something cursorily on the internet.

This kind of browsing is a highly effective way of deepening your specialist

Correspondence to: Dr John Launer, Faculty Development, Health Education England, Stewart House, 32 Russell Square, London WC1B 5DN, UK: john.launer@nwl.hee.nhs.uk knowledge too. If you go to your library regularly and look through all the main journals in your own fields of interest, you will find yourself reading a far wider range of articles than you could ever subscribe to, or could access on the web. You may be gripped by an article you could easily have read at home-except that the journal in question is still sitting in its wrapper in a pile in the bathroom, or available on a link you have 'favourited' but never clicked. Your attention may be grabbed by a paper you originally skimmed on the screen, but realise is far more interesting on the printed page: a phenomenon that is hard to explain, but a common experience for library users.

\section{TRUMPING ELECTRONIC SEARCHES}

Surprisingly, you also may find that a search of journals in a library trumps an electronic search, even when carrying out a literature review for research purposes. There are probably only five or six journals in your speciality that consistently carry first class original research, and you can no doubt name all of them. In a library, you can look for the bound volumes of each of them for the last ten years, and do a manual search of their indexes. You will almost certainly track down over fifty per cent of the articles relevant to your needs. If you follow up the references at the end of in those articles, you will probably find most of the remaining fifty per cent. Indeed, you will notice the same sources being mentioned again and again. You may have to repeat the exercise using a computerised search engine and Boolean logic, simply in order to convince your supervisor or an editor that you have done a proper job! You will still find that the ratio between useful information and scholarly dross that you got in the library is far better than anything you achieved by using a computer. If you really want to double-check you have covered the ground, write to the six leading authors you identify and ask them to recommend their own favourite reviews of the subject. The responses you get will demonstrate that the human touch beats databases every time.

Libraries consist of more than shelves and books, and it is well worth being nice to librarians and regularly asking for their help. The vast majority are phenomenally adept at navigating the world wide web and tracking down the references you cannot find yourself. In general, they are also very kind to library users like myself who are nervous of being sucked into an electronic vortex when using search engines. At the same time, nothing seems to delight them more than being given a slip of paper with a request for some obscure volume from the 1950 s, enabling them to vanish into the basement and return half an hour later, triumphantly blowing the dust off a book that was last borrowed and rubber-stamped in its year of publication. There is something magical in such moments. You and the librarian are reliving an experience that must have been shared by every scholarly generation from ancient Egypt to today.

If you have seen the latest James Bond movie, 'Skyfall', you will know that the villain tries to achieve domination over the world through the use of fantastical computer technology. Yet at the end of the movie, in a remote chapel in Scotland, he is finally dispatched by a dirk-a Scottish dagger-thrown deftly between his ribs. The dagger belongs to Bond's old family retainer Kincade, who produces it with the memorable line: 'Sometimes the old ways are the best.' The moral of the statement, and of the movie, is that new technology may be dazzlingly powerful, but it can never outdo the simple and trusted methods of the past. We may not take such a polarised a view in medicine, but there is still some truth to it. Next time you spend an evening looking at Twitter, LinkedIn, Researchgate, and Facebook, consider setting aside half an hour in your diary the following day to rediscover all the benefits of the old ways'-in a library.

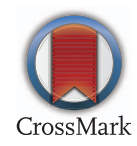

To cite Launer J. Postgrad Med J 2014;90:606.

Postgrad Med J 2014;90:606.

doi:10.1136/postgradmedj-2014-132997

\section{REFERENCES}

1 International Conference on Residency Education. Residency education and care in the digital age. http://www.royalcollege.ca/portal/page/portal/rcl events/icre

2 Launer J. The Age of Twitter. Postgrad Med J 2013; 89:675-6. 